\title{
Fracture load of 3D printed PEEK inlays compared with milled ones, direct resin composite fillings, and sound teeth
}

\author{
Alexander Prechtel ${ }^{1}$ (D) $\cdot$ Bogna Stawarczyk $^{1} \cdot$ Reinhard Hickel $^{2} \cdot$ Daniel Edelhoff $^{1} \cdot$ Marcel Reymus $^{2}$
}

Received: 3 September 2019 / Accepted: 17 January 2020 / Published online: 27 January 2020

(C) The Author(s) 2020

\begin{abstract}
Objective The objective of this in vitro study was to investigate fracture load, fracture types, and impact of chewing simulation of human molars restored with 3D printed indirect polyetheretherketone (PEEK) inlays and compare these with milled indirect PEEK inlays, direct resin composite fillings, and sound teeth.

Materials and methods A total of 112 molars with form congruent class I cavities were restored with ( $n=16 /$ group) 3D printed indirect PEEK inlays via fused layer manufacturing (FLM): (1) Essentium PEEK (ESS), (2) KetaSpire PEEK MS-NT1 (KET), (3) VESTAKEEP i4 G (VES), (4) VICTREX PEEK 450G (VIC), (5) milled indirect PEEK inlays JUVORA Dental Disc 2 (JUV), and (6) direct resin composite fillings out of Tetric EvoCeram (TET). Sound teeth (7) acted as positive control group. Half of the specimens of each group $(n=8)$ were treated in a chewing simulator combined with thermal cycling $(1.2$ million $\times 50 \mathrm{~N}$; $12,000 \times 5^{\circ} \mathrm{C} / 55^{\circ} \mathrm{C}$ ). Fracture load and fracture types of all molars were determined. Statistical analyses using KolmogorovSmirnov test and two-way ANOVA with partial eta squared $\left(\eta_{\mathrm{p}}{ }^{2}\right)$ followed by Scheffé post hoc test, chi square test and Weibull modulus $m$ with 95\% confidence interval were computed $(p<0.05)$.

Results ESS and TET demonstrated the lowest fracture load with a minimum of $956 \mathrm{~N}$, whereas sound molars showed the highest values of up to $2981 \mathrm{~N}$. Chewing simulation indicated no impact $(p=0.132)$. With regard to Weibull modulus, KET presented a lower value after chewing simulation than JUV, whereas TET had the highest value without chewing simulation. All indirect restorations revealed a tooth fracture (75-100\%), direct resin composite fillings showed a restoration fracture (87.5\%), and $50 \%$ of the sound teeth fractured completely or had cusp fractures.

Conclusions All 3D printed and milled indirect PEEK inlays as well as the direct resin composite fillings presented a higher fracture load than the expected physiological and maximum chewing forces.

Clinical relevance 3D printing of inlays out of PEEK via FLM provided promising results in mechanics, but improvements in terms of precision and esthetics will be required to be practicable in vivo to represent an alternative dental material.
\end{abstract}

Keywords PEEK · 3D printing · Additive manufacturing $\cdot$ Fused layer manufacturing (FLM) $\cdot$ Chewing simulation $\cdot$ Fracture load

\section{Introduction}

Additive manufacturing (AM), also known as rapid prototyping, includes the manufacturing by $3 \mathrm{D}$ printing and enables the development of new material classes with

Alexander Prechtel

Alexander.Prechtel@med.uni-muenchen.de

1 Department of Prosthetic Dentistry,

Ludwig-Maximilians-Universität Munich, Goethestrasse 70, 80336 Munich, Germany

2 Department of Conservative Dentistry and Periodontology, Ludwig-Maximilians-Universität Munich, Goethestrasse 70, 80336 Munich, Germany more efficient and material-saving fabrication processes. Already today, 3D printing has a wide range of applications, such as dental restorations, implants, surgical guides, orthodontic devices, and physical models [1]. AM is also applied successfully in dental research, education, and training [2].

There are many advantages of 3D printing in dentistry, which improve the daily work of a dentist or dental technician and also the quality of patient life [3]. One of the biggest advantages is that patient-individual parts can be developed and produced with a minimum of time, amount of material, and cost. The mostly required postprocessing (e.g., removal of support structures, surface polishing) and an anisotropic behavior (mechanical properties depend on the printing direction) have to be mentioned as disadvantages [4]. 
AM is used in a digital workflow since the 1980s and consists of data acquisition (e.g., intraoral scan of patient teeth), designing the desired object by a CAD (computeraided-design) software, dividing the object into many layers by a slicing software, and finally computer-aided manufacturing (CAM) with a 3D printing machine [5]. There are several different 3D printing techniques in dentistry such as stereolithography (SLA), selective laser sintering (SLS), digital light processing (DLP), and fused layer manufacturing (FLM) [4]. Since 2013, FLM is suitable for processing high-performance polymers from the group of polyaryletherketone (PAEK) [6]. PAEKs are semi-crystalline linear aromatic thermoplastics, whereby the number of ether and ketone bindings provides different variants, such as polyetherketoneketone (PEKK) and polyetheretherketone (PEEK), which have slightly different mechanical and thermal properties. In dentistry, PEEK is most common since it has outstanding properties, such as excellent biocompatibility, non-cytotoxical and bio-inert behavior, favorable mechanical properties, radio translucency, bone-like Young's modulus of 3-4 GPa and low plaque affinity and chemical stability [7]. Until now, PEEK has been used in dentistry for removable and fixed dental prostheses, implants, and implant abutments as well as orthodontic devices [8], whereas in literature, it is mostly mentioned in relation to prosthetics [9]. PEEK was predominantly processed out of industrially pre-pressed pellets or granular form and $\mathrm{CAD} / \mathrm{CAM}$-supported milled out of prefabricated blanks. Producing dental restorations additively via FLM out of PEEK is still hardly widespread. With the FLM technique, the solid PEEK filament is melted in a nozzle and placed layer by layer onto the building platform in a specific laydown pattern. Critical factors are the required continuously high temperatures of over $350{ }^{\circ} \mathrm{C}$, a special heat management of the nozzle, building platform and chamber to avoid nozzle blockage or material degradation and to achieve firm layer bonding as well as low component warpage [10].

Most restorative procedures involve massive reductions of tooth structure as the teeth have to be prepared. For example, when preparing class II cavities for an indirect restoration, more tooth structure is lost compared with preparations for direct restorations, which results in a lower tooth fracture strength [11]. Thus, occlusal preparations with a width of one-third of the intercuspal distance weaken the strength of a tooth by $60 \%$ [12]. However, indirect restorations offer some advantages over direct ones, such as better proximal and occlusal designs, higher wear resistance, superior mechanical properties, and more precise marginal adaptation, resulting in reduced microleakage [13].

Weibull statistics is particularly suitable in dental material research to characterize the failure and reliability of brittle materials such as ceramics and polymers [14]. The Weibull modulus $m$ is a parameter for the dispersion of the strength values and provides information about the structural homogeneity of one material [15].

Besides this parameter, fracture load and durability to thermal stress are important factors that should be investigated before applying a new dental material in order to achieve an optimal clinical performance and a high long-term success.

Therefore, measuring fracture load and using a chewing simulator are proven in vitro methods to simulate mechanical properties of the material under masticatory movement and force effectively [16].

The aim of this study was to investigate the impact of chewing simulation combined with thermocycling on the fracture load of different 3D printed class I inlay materials compared with one milled PEEK material, one conventional direct resin composite material, and sound teeth. The null hypotheses tested were (1) the various restoration materials show no differences in the fracture load and (2) the fatigue process of chewing simulation has no impact on the fracture load of the restored teeth.

\section{Materials and methods}

A total number of 112 human maxillary and mandibular extracted molars free of visible cracks, carious lesions, or restorative materials were collected for this study, which were stored in $0.5 \%$ chloramine $\mathrm{T}$ trihydrate (Carl Roth, Karlsruhe, Germany, CAS-No: 7080-50-4; Lot-No: 285228116) at room temperature $\left(23^{\circ} \mathrm{C}\right)$ for a maximum of 1 week after extraction and then in distilled water at $5{ }^{\circ} \mathrm{C}$. All teeth were thoroughly cleaned, and their roots were embedded up to the cementoenamel junction (CEJ) in a self-cured acrylic resin (ScandiQuick A and B, ScanDia, Hagen, Germany, Lot-No: 09201 and 09202) in round metal molds (Fig. 1a). Before measurement, the embedded molars were stored in distilled water at $37^{\circ} \mathrm{C}$ in an incubator (HeraCell 150 , Heraeus, Hanau, Germany), which was changed every week. All molars were randomly divided into seven groups ( $n=16$ teeth) with different restoration materials (Table 1). Occlusal class I cavities (vestibular-oral width of $3.0 \mathrm{~mm}$, distal-mesial width of $6.5 \mathrm{~mm}$, occlusal reduction of $4.0 \mathrm{~mm}$, convergence angle of $6^{\circ}$ ) were prepared, except one group that served as an unprepared and unrestored control group. The preparations were made under permanent water cooling at 40,000 $\mathrm{min}^{-1} / \mathrm{rpm}$ with a conical diamond bur (6848.314.031, Gebr. Brasseler, Lemgo, Germany) in a high-speed handpiece (Perfecta 900, W\&H, Laufen, Germany), which was mounted in a dental parallel surveyor (F4 basic, DeguDent GmbH, Hanau, Germany). Care was taken to always prepare cavities of the same size and depth, which was ensured with markings on tooth and bur (Fig. 1a). The molars were subsequently restored with indirect and direct restorations. 
Fig. 1 Workflow. a Preparation of a class I cavity. b Designing an inlay by CAD software. $\mathbf{c}$ Printing via FLM. d Adhesively inserted inlay. e Chewing simulation. $\mathbf{f}$ Fracture load measurement

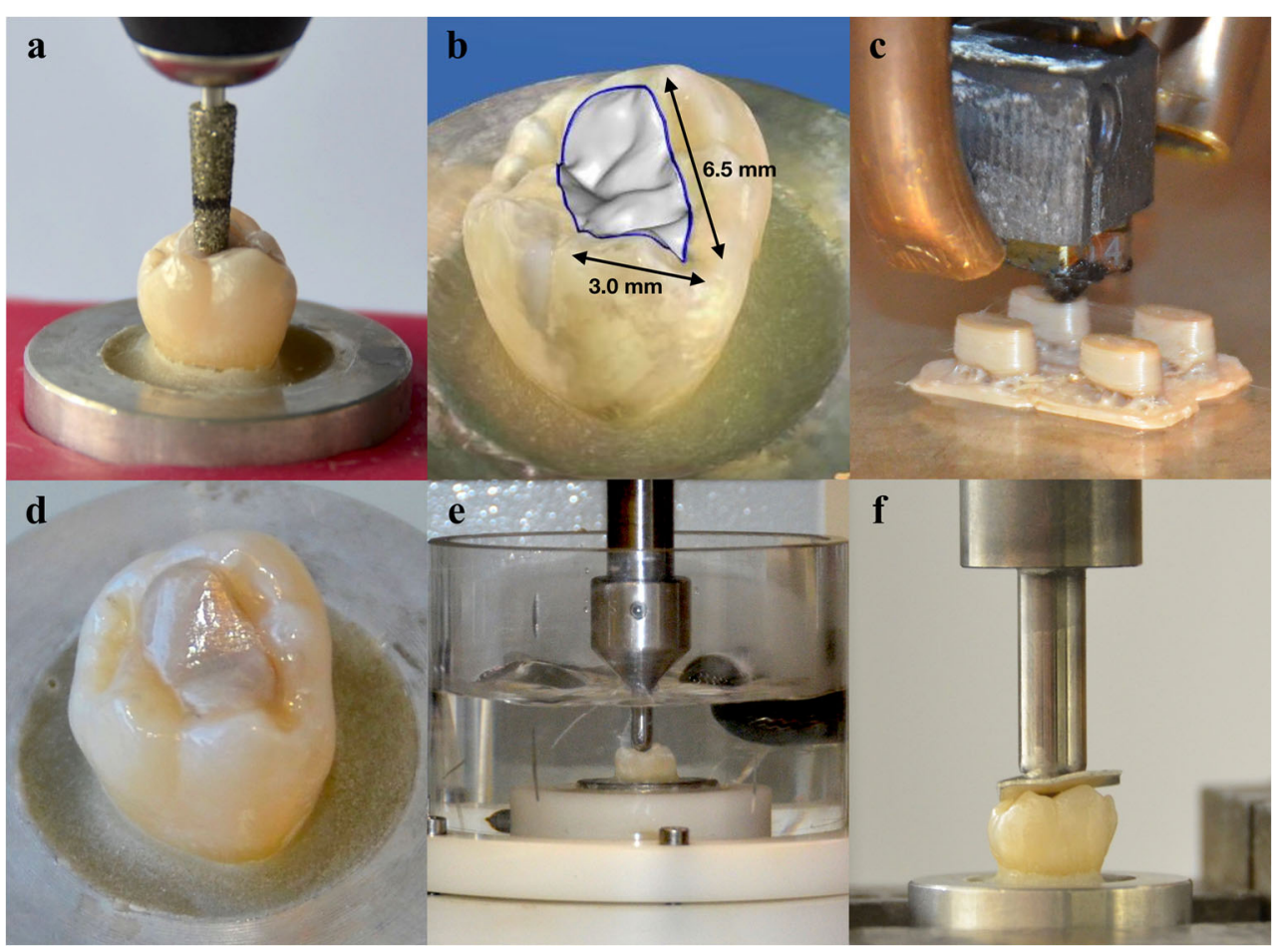

For this purpose, the prepared teeth for the indirect restorations were scanned with an optical 3D camera (CEREC Omnicam, Dentsply Sirona, Bensheim, Germany), inlays were designed by a CAD software (CEREC SW 4.6.1, Dentsply Sirona), and files were created in STL format (inLab CAD SW 18.1, Dentsply Sirona) (Fig. 1b). From each printable PEEK material (Essentium PEEK (ESS), KetaSpire PEEK MS-NT1 (KET), VESTAKEEP i4 G (VES), and VICTREX PEEK 450G (VIC)) (Table 1), 16 inlays were additively manufactured out of a filament (diameter $1.75 \mathrm{~mm}$ ) via FLM with the printer HTRD1.2 (KUMOVIS, Munich, Germany) (Fig. 1c). Before manufacturing, the filament was dried in an oven (Heraeus RT 360 , Heraeus) at $120^{\circ} \mathrm{C}$ for $12 \mathrm{~h}$ in order to extract moisture and avoid artefacts such as air inclusions [6]. For better comparability, all materials were printed with the same parameters (Table 2). After the printing process was finished, the inlays were immediately removed from the building platform and cooled down at room temperature. Thus, support structures had to be removed with milling instruments (H73EF.104.014 and H136EF.104.016, Gebr.

Table 1 Summary of used materials, abbreviations, compositions, manufacturer, and lot numbers

\begin{tabular}{|c|c|c|c|c|c|}
\hline & Material & Abbreviation & Composition & Manufacturer & Lot no \\
\hline \multirow{4}{*}{$\begin{array}{l}\text { 3D printed } \\
\text { indirect PEEK } \\
\text { inlays }\end{array}$} & Essentium PEEK & ESS & Polyetheretherketon, unfilled & $\begin{array}{l}\text { Essentium Inc., Pflugerville, } \\
\text { USA }\end{array}$ & 1-80601 \\
\hline & $\begin{array}{l}\text { KetaSpire }{ }^{\circledR} \text { PEEK } \\
\text { MS-NT1 }\end{array}$ & KET & Polyetheretherketon, unfilled & $\begin{array}{l}\text { Solvay Specialty Polymers } \\
\text { USA, L.L.C., Alpharetta } \\
\text { GA, USA }\end{array}$ & 1850009004 \\
\hline & $\begin{array}{l}\text { VESTAKEEP® i4 } \\
\text { G (exp. } \\
\text { material) }\end{array}$ & VES & Polyetheretherketon, unfilled & $\begin{array}{l}\text { Evonik Industries AG, } \\
\text { Essen, Germany }\end{array}$ & $\begin{array}{l}\text { "testing grade" } \\
\text { version }\end{array}$ \\
\hline & $\begin{array}{l}\text { VICTREX }{ }^{\circledR} \\
\text { PEEK 450G }\end{array}$ & VIC & Polyetheretherketon, unfilled & $\begin{array}{l}\text { Victrex plc., Thornton } \\
\text { Cleveleys, UK }\end{array}$ & 7082 \\
\hline $\begin{array}{l}\text { Milled indirect } \\
\text { PEEK inlays }\end{array}$ & $\begin{array}{l}\text { JUVORA }^{\mathrm{TM}} \\
\text { Dental Disc } 2\end{array}$ & JUV & Polyetheretherketon, unfilled & $\begin{array}{l}\text { JUVORA Ltd., Thornton } \\
\text { Cleveleys, UK }\end{array}$ & WO000042IDML \\
\hline $\begin{array}{l}\text { Direct resin } \\
\text { composite } \\
\text { fillings }\end{array}$ & Tetric EvoCeram® & TET & $\begin{array}{l}\text { BisGMA, UDMA, DMDMA, Bariumglass, } \\
\mathrm{YbF}_{3} \text {, mixed oxide, pre-polymerized fillers }\end{array}$ & $\begin{array}{l}\text { Ivoclar Vivadent } \mathrm{GmbH} \\
\text { Schaan, Liechtenstein }\end{array}$ & Y08778 \\
\hline Control group & $\begin{array}{l}\text { Sound human } \\
\text { molars }\end{array}$ & - & - & - & - \\
\hline
\end{tabular}

Bis GMA, bisphenol-A-diglycidyldimethacrylate; $D M D M A$, decamethylendimethacrylate; $U D M A$, urethane dimethacrylate; $Y b F_{3}$, ytterbiumtrifluorid 
Table 2 Printing parameters and technical specifications of HTRD1.2

\begin{tabular}{ll}
\hline Nozzle temperature & $390{ }^{\circ} \mathrm{C}$ \\
Nozzle diameter & $0.4 \mathrm{~mm}$ \\
Heated building chamber & $100{ }^{\circ} \mathrm{C}$ \\
Cooling temperature & $120^{\circ} \mathrm{C}$ \\
Heated building platform & $220{ }^{\circ} \mathrm{C}$ \\
Ventilation & Heated laminar airflow \\
Layer height & $0.15 \mathrm{~mm}$ \\
Extrusion width & $0.30 \mathrm{~mm}$ \\
Printing speed & $300 \mathrm{~mm} / \mathrm{min}$ \\
\hline
\end{tabular}

Brasseler) in a handpiece (KaVo EWL K9, KaVo Dental, Biberach/ Riß, Germany), the inlay had to be adapted individually to its cavity, and the occlusal surface had to be recontoured (Fig. 2). Such postprocessing also had to be performed on the milled inlays made out of JUVORA Dental Disc 2 (JUV) (Table 1). These were milled out of a disc with a CAD/CAM milling machine (ZENOTEC 4030, Wieland Dental + Technik, Pforzheim, Germany).

After all inlays had been adequately adapted, they were adhesively inserted into the cavities. All inlays were airabraded with $50-\mu \mathrm{m} \mathrm{Al}_{2} \mathrm{O}_{3}$ powder under $0.2 \mathrm{MPa}$ for $10 \mathrm{~s}$ at a distance of $10 \mathrm{~mm}$ and in an angle of $45^{\circ}$ (basic Quattro IS; Renfert, Hilzingen, Germany), conditioned with a thin film of visio.link (bredent, Senden, Germany) and light-cured for $30 \mathrm{~s}$ (bre. Lux LED N, bredent). The tooth-hard tissues were pre-treated using total etch technique, in which the enamel was etched for $30 \mathrm{~s}$ and the dentin for $15 \mathrm{~s}$ with a $35 \%$ phosphoric acid $\left(\mathrm{H}_{3} \mathrm{PO}_{4}\right)$ (Total Etch, Ivoclar Vivadent, Schaan, Liechtenstein). Thereafter, according to the manufacturer's instructions, Syntac Primer (Ivoclar Vivadent) was applied for at least $15 \mathrm{~s}$, Syntac Adhesive (Ivoclar Vivadent) for $10 \mathrm{~s}$, and both were gently air-dried. Subsequently, a thin layer of Heliobond (Ivoclar Vivadent) was applied in all cavities and light-cured for $10 \mathrm{~s}$ (Elipar S10, 3M, Seefeld, Germany) only for the direct composite fillings. The dual-curing Variolink Esthetic (shade warm+, Ivoclar Vivadent) was used as luting resin composite for the inlays, which was light- cured occlusally for at least $20 \mathrm{~s}$ (Elipar S10, $3 \mathrm{M}$ ) after the inlay was inserted. Finally, the bonded inlays were polished to high gloss with goat hair brushes (bredent) and polishing paste (Abraso Starglanz, bredent) for $1 \mathrm{~min}$ at $3000 \mathrm{~min}^{-1} / \mathrm{rpm}$ (KaVo EWL K9, KaVo Dental) (Fig. 1d).

The direct restorations were performed with the nanohybrid resin composite Tetric EvoCeram (TET) (shade A3, Ivoclar Vivadent) (Table 1). The cavities were filled using an incremental filling technique, where each layer (max. $2 \mathrm{~mm}$ ) was light-cured for $20 \mathrm{~s}$ (Elipar S10, 3M). The polishing was carried out with a two-step polishing system (94028M.204.130 and 94028F.204.130, Gebr. Brasseler) for $1 \mathrm{~min}$ at $6000 \mathrm{~min}^{-1} / \mathrm{rpm}$ under permanent water cooling.

Eight teeth were selected from each of the seven groups. They were mounted in a chewing simulator (CS-4.8, SD Mechatronics, Feldkirchen-Westerham, Germany) for 1.2 million masticatory cycles with a frequency of $1.20 \mathrm{~Hz}$ and force of $50 \mathrm{~N}$ (Fig. 1e). The chambers were filled alternately for 12,000 cycles for $30 \mathrm{~s}$ each with 5 and $55{ }^{\circ} \mathrm{C}$ distilled water, so that in addition to mechanical loading, thermal cycling also took place simultaneously. Stainless steel balls out of chromium-nickel 1.4301 (diameter: $4.5 \mathrm{~mm}$; SD Mechatronics) were used as antagonists and were aimed at a three-point occlusal contact. They moved in vertical $(1.0 \mathrm{~mm})$ and lateral $(0.7 \mathrm{~mm})$ directions as it occurs during physiological chewing. Subsequently, each single tooth was examined under a light microscope (Leica DM2700 M, Leica Microsystems GmbH, Wetzlar, Germany) for fractures that might have occurred during mechanical and thermal exposure. After this simulation, fracture load measurements were performed in a universal testing machine (Zwick 1445, ZwickRoell, Ulm, Germany). The embedded tooth was fixed into the holding device of the machine, and a tin foil (thickness $0.5 \mathrm{~mm}$; DENTAURUM, Ispringen, Germany, Lot-No: 469721) was placed between the stamp and the tooth to ensure a homogenous force distribution and to avoid local force peaks (Fig. 1f). Then, an increasing load was applied perpendicularly to the central fossa with a stamp of hemispherical shape (diameter $6 \mathrm{~mm}$ ) until failure occurred (crosshead speed $1 \mathrm{~mm} / \mathrm{min}$ ). Force values were recorded
Fig. 2 Postprocessing of the printed inlays. a Removing of support structure. b Adaptation to the cavity. c Occlusal recontouring

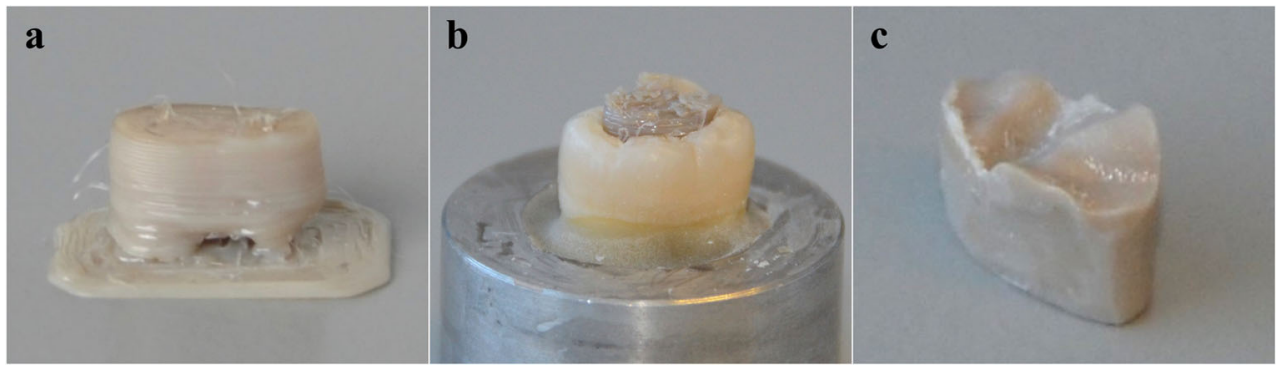


automatically in Newton (N) as soon as the maximum fracture load decreased by $50 \%$ until an initial crack or total fracture was detected (testXpert II V3.6, ZwickRoell). The fracture types were classified as follows: tooth fracture (a), cusp fracture (b), and restoration fracture (c) (Table 5).

All measured data were analyzed with the SPSS statistic program (version 25.0.0.1, IBM, Armonk, NY, USA). The assumption of normality was tested using KolmogorovSmirnov test. Two-way ANOVA with partial eta squared $\left(\eta_{\mathrm{p}}{ }^{2}\right)$ followed by Scheffé post hoc test was computed to verify the impact of chewing simulation on fracture load. Weibull distribution parameter (Weibull modulus $m$ ) was calculated using the maximum likelihood estimation method and 95\% confidence interval (95\% CI) [17]. Chi square $\left(\mathrm{chi}^{2}\right)$ test and Ciba-Geigy tables were used to analyze the relative frequencies of fracture types together with the corresponding $95 \%$ confidence intervals (CI) [18]. In all analyses, the level of significance was set to $p<0.05$.

\section{Results}

The descriptive statistics is shown in Table 3 . The Kolmogorov-Smirnov test indicated no violation of normal distribution, so data were analyzed parametrically. According to two-way ANOVA, the restoration material showed an influence on the fracture load $(p<0.001)$, whereas chewing simulation had no impact $(p=0.132)$ (Table 4).

ESS and TET showed the significant lowest fracture load down to a minimum of $956 \mathrm{~N}$ (Fig. 3). VIC was together with VES, KET, and JUV in the same value range. The sound molars presented the highest fracture load values of up to $2981 \mathrm{~N}(p<0.001)$.
The microscopic examinations showed that the chewing simulation combined with thermal cycling did not cause any fractures in all investigated teeth.

Regarding Weibull modulus, KET had a significantly lower value than JUV for the groups with performed chewing simulation, whereas TET showed for the groups without chewing simulation the significant highest Weibull modulus (Table 3).

With respect to fracture types, differences between the groups were observed (chi ${ }^{2}$ test $p<0.001$ ). All indirect restorations and sound molars, regardless of the fatigue process, showed a significantly higher tooth fracture rate $(75-100 \%)$ than TET (Table 5). All 3D printed inlays remained intact after the fracture load test $(100 \%)$. Only one milled inlay out of JUV failed due to a restoration fracture (12.5\%). TET showed a significantly higher restoration fracture rate than all the other groups $(87.5 \%)$. With regard to cusp fractures, the untreated molars presented the significantly highest relative frequencies $(50 \%)$.

\section{Discussion}

This study investigated the fracture load of 3D printed indirect PEEK inlays in comparison with milled ones, conventionally direct composite fillings, and sound human molars under the influence of chewing simulation with combined thermal cycling. In general, all tested indirect and direct restorations demonstrated a higher fracture load compared with the expected physiological chewing forces of 110-125 $\mathrm{N}[19,20]$ and maximum bite forces in the molar region of up to $909 \mathrm{~N}$ [21, 22]. However, the first null hypothesis had to be rejected, since the various materials indicated differences in fracture

Table 3 Fracture load (mean \pm standard deviation) and Weibull modulus (95\% confidence intervals) according to the restoration material and fatigue process

\begin{tabular}{|c|c|c|c|c|c|c|}
\hline \multirow[t]{2}{*}{ Restoration material } & \multicolumn{3}{|c|}{ With chewing simulation } & \multicolumn{3}{|c|}{ Without chewing simulation } \\
\hline & Mean $\pm \mathrm{SD}($ in $N)$ & $\begin{array}{l}95 \% \mathrm{CI} \text { (in } \\
N)\end{array}$ & $\begin{array}{l}\text { Weibull modulus (95\% } \\
\text { CI) }\end{array}$ & $\begin{array}{l}\text { Mean } \pm \mathrm{SD} \text { (in } \\
N)\end{array}$ & $\begin{array}{l}95 \% \mathrm{CI} \text { (in } \\
N)\end{array}$ & $\begin{array}{l}\text { Weibull modulus (95\% } \\
\text { CI) }\end{array}$ \\
\hline Essentium PEEK & $956( \pm 222)^{\mathrm{a}}$ & $769.1 ; 1151$ & $4.2(1.9 ; 8.6)^{\mathrm{AB}}$ & $1062( \pm 300.4)^{\mathrm{a}}$ & $809.8 ; 1323$ & $4.1(1.8 ; 8.5)^{\mathrm{AB}}$ \\
\hline $\begin{array}{l}\text { KetaSpire PEEK } \\
\text { MS-NT1 }\end{array}$ & $1715( \pm 571.3)^{\mathrm{bc}}$ & $1227 ; 2202$ & $2.7(1.2 ; 5.6)^{\mathrm{A}}$ & $1681( \pm 416.8)^{\mathrm{bc}}$ & $1323 ; 2039$ & $4.4(2.0 ; 9.2)^{\mathrm{AB}}$ \\
\hline VESTAKEEP i4 G & $1712( \pm 325.0) * \mathrm{bc}$ & $1430 ; 1993$ & $5.3(2.4 ; 11.0)^{\mathrm{AB}}$ & $1633( \pm 431.0)^{\mathrm{bc}}$ & $1262 ; 2003$ & $3.8(1.7 ; 7.9)^{\mathrm{AB}}$ \\
\hline VICTREX PEEK 450G & $1392( \pm 444.1)^{\mathrm{bc}}$ & $1010 ; 1773$ & $3.4(1.5 ; 7.0)^{\mathrm{AB}}$ & $1800( \pm 324.8)^{\mathrm{bc}}$ & $1518 ; 2081$ & $6.3(2.9 ; 13.0)^{\mathrm{AB}}$ \\
\hline JUVORA Dental Disc 2 & $1984( \pm 291.9)^{\mathrm{c}}$ & $1730 ; 2238$ & $7.4(3.4 ; 15.3)^{\mathrm{B}}$ & $1756( \pm 511.2)^{\mathrm{c}}$ & $1318 ; 2193$ & $3.4(1.5 ; 7.1)^{\mathrm{AB}}$ \\
\hline Tetric EvoCeram & $1189( \pm 307.9)^{\mathrm{ab}}$ & $930.8 ; 1456$ & $3.7(1.6 ; 7.6)^{\mathrm{AB}}$ & $1277( \pm 181.6)^{\mathrm{ab}}$ & $1115 ; 1439$ & $7.7(3.2 ; 16.0)^{\mathrm{B}}$ \\
\hline Sound human molars & $2385( \pm 583.8)^{\mathrm{d}}$ & $1886 ; 2883$ & $3.8(1.7 ; 8.0)^{\mathrm{AB}}$ & $2981( \pm 706.9)^{\mathrm{d}}$ & $2379 ; 3581$ & $4.3(1.9 ; 8.9)^{\mathrm{AB}}$ \\
\hline
\end{tabular}


Table 4 Two-way ANOVA results of fracture load according to the restoration material and chewing simulation

\begin{tabular}{lllllll}
\hline & $\begin{array}{l}\text { Sum of } \\
\text { squares }\end{array}$ & $d f$ & $\begin{array}{l}\text { Mean } \\
\text { squares }\end{array}$ & $F$ & $p$ & $\eta_{p}{ }^{2}$ \\
\hline Restoration material & $27,194,106$ & 6 & $4,532,351$ & 24.9 & $<0.001$ & 0.604 \\
Chewing simulation & 419,245 & 1 & 419,245 & 2.30 & 0.132 & 0.023 \\
$\begin{array}{l}\text { Restoration material } \times \text { chewing } \\
\quad \text { simulation }\end{array}$ & $1,980,256$ & 6 & 330,043 & 1.81 & 0.104 & 0.100 \\
$\quad$ Error & $17,837,880$ & 98 & 182,019 & & & \\
$\quad$ Total & $363,620,932$ & 112 & & & & \\
\hline
\end{tabular}

load. ESS and TET showed the lowest fracture load of all tested groups. Although ESS was processed like all the other filaments as well as the inlays were inserted according to the same procedure, the low fracture load might be explained by the material composition, like lower filler degree or different filler types for example. Unfortunately, this is difficult to state due to a lack of information by the manufacturer. It might also be possible that each filament needs individual printing parameters to achieve better mechanics. Since the printed components have an anisotropic behavior, the printing direction and thus the position of the support structure can decisively influence the mechanical properties. In the present study, the support structure was attached to the occlusal surface of the inlay, whereby the printing direction was parallel to the direction of measurement of the fracture load, which is supposed to lead to optimal mechanics [23].

TET also had the lowest fracture load, because direct composite fillings placed in a cavity in several layers often exhibit a degree of inhomogeneity in form of small voids, insufficiently polymerized parts, and polymerization shrinkage stress, resulting in lower mechanics [24]. Also, because of a higher polymer content than the semi-crystalline PEEK materials, the water absorption is higher. This might explain that the resin composite reacted sensitively to the water storage and chewing simulation with thermal cycling [25].

The sound molars presented by far the highest fracture load. Unfortunately, cavity preparations usually lead to an extended loss of enamel and dentin. As a consequence, the tooth loses considerable stability and becomes more vulnerable to fractures. Mondelli et al. have found out that a class I cavity reduces the strength of the tooth less than a class II preparation with equal width, so marginal ridges provide a tooth stability [26]. The buccolingual width is also an influential factor on flexural strength. In the present investigation, the width was maximum one-third of the intercuspal distance. However, even with this narrow occlusal cavity, the tooth is already weakened compared with an uncavitated tooth [12]. The etiology of a tooth fracture is complex and multifactorial. While intact teeth therefore rarely fracture under chewing load, teeth weakened by preparation of cavities, caries, endodontic treatments, genetic disorders like amelo-/ dentinogenesis imperfecta or molar-incisor hypomineralization (MIH) and periodontal lesions may spontaneously fracture under physiological mastication load, so

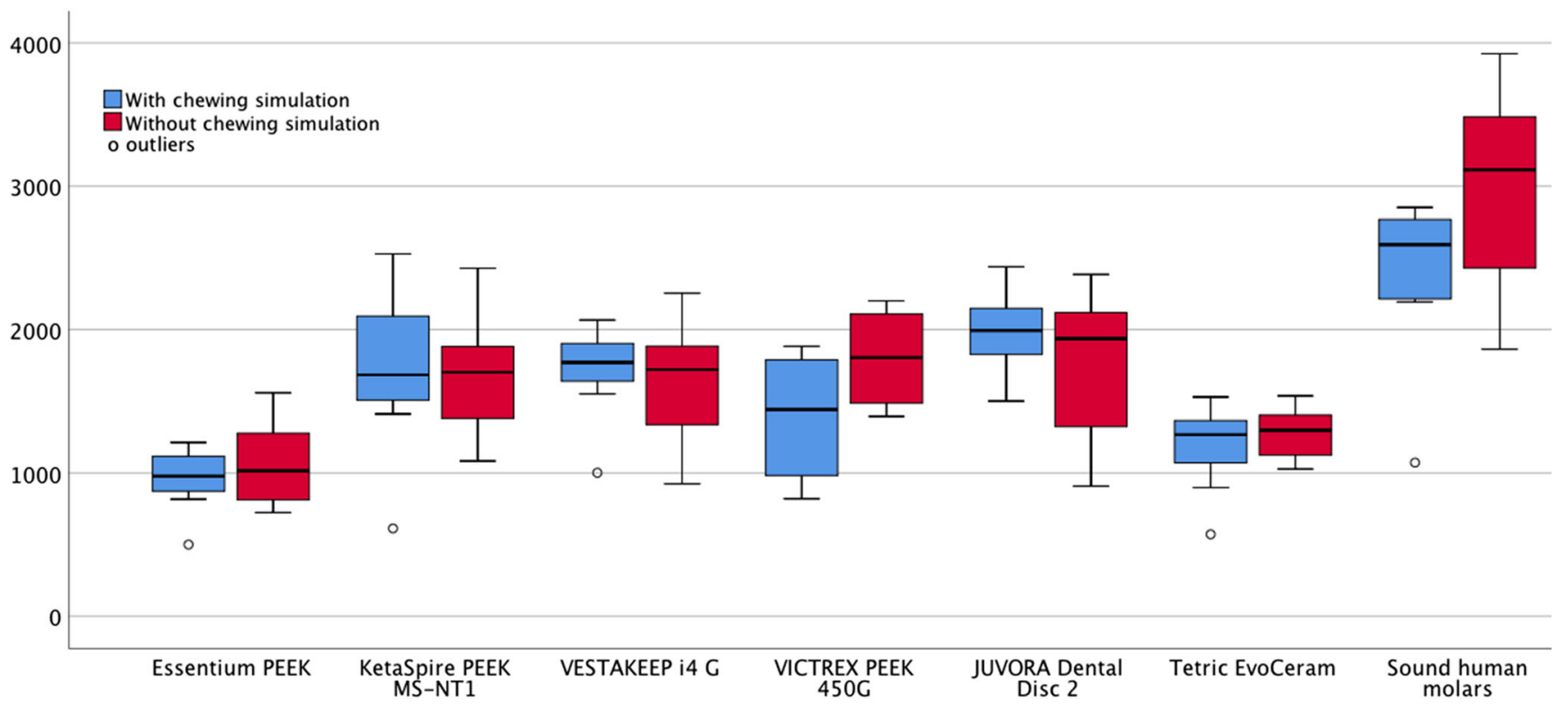

Fig. 3 Fracture load (in $N$ ) of all tested materials with and without chewing simulation presented in boxplot 
Table 5 Relative frequencies (95\% confidence intervals) of the fracture types according to the restoration material and fatigue process

\begin{tabular}{|c|c|c|c|c|}
\hline Restoration material & Fatigue process & Tooth fracture (\%) & Cusp fracture (\%) & Restoration fracture (\%) \\
\hline \multirow[t]{2}{*}{ Essentium PEEK } & $\begin{array}{l}\text { With chewing } \\
\text { simulation }\end{array}$ & $100(62 ; 100)^{\mathrm{c}}$ & $0(0 ; 37)^{\mathrm{a}}$ & $0(0 ; 37)^{\mathrm{a}}$ \\
\hline & $\begin{array}{l}\text { Without chewing } \\
\text { simulation }\end{array}$ & $87.5(46 ; 100)^{\mathrm{c}}$ & $12.5(0 ; 53)^{\mathrm{a}}$ & $0(0 ; 37)^{\mathrm{a}}$ \\
\hline \multirow[t]{2}{*}{ KetaSpire PEEK MS-NT1 } & $\begin{array}{l}\text { With chewing } \\
\text { simulation }\end{array}$ & $100(62 ; 100)^{\mathrm{c}}$ & $0(0 ; 37)^{\mathrm{a}}$ & $0(0 ; 37)^{\mathrm{a}}$ \\
\hline & $\begin{array}{l}\text { Without chewing } \\
\text { simulation }\end{array}$ & $100(62 ; 100)^{c}$ & $0(0 ; 37)^{\mathrm{a}}$ & $0(0 ; 37)^{\mathrm{a}}$ \\
\hline \multirow[t]{2}{*}{ VESTAKEEP i4 G } & $\begin{array}{l}\text { With chewing } \\
\text { simulation }\end{array}$ & $87.5(46 ; 100)^{\mathrm{c}}$ & $12.5(0 ; 53)^{\mathrm{a}}$ & $0(0 ; 37)^{\mathrm{a}}$ \\
\hline & $\begin{array}{l}\text { Without chewing } \\
\text { simulation }\end{array}$ & $100(62 ; 100)^{c}$ & $0(0 ; 37)^{\mathrm{a}}$ & $0(0 ; 37)^{\mathrm{a}}$ \\
\hline \multirow[t]{2}{*}{ VICTREX PEEK 450G } & $\begin{array}{l}\text { With chewing } \\
\text { simulation }\end{array}$ & $100(62 ; 100)^{c}$ & $0(0 ; 37)^{\mathrm{a}}$ & $0(0 ; 37)^{\mathrm{a}}$ \\
\hline & $\begin{array}{l}\text { Without chewing } \\
\text { simulation }\end{array}$ & $100(62 ; 100)^{\mathrm{c}}$ & $0(0 ; 37)^{\mathrm{a}}$ & $0(0 ; 37)^{\mathrm{a}}$ \\
\hline \multirow[t]{2}{*}{ JUVORA Dental Disc 2} & $\begin{array}{l}\text { With chewing } \\
\text { simulation }\end{array}$ & $100(62 ; 100)^{\mathrm{c}}$ & $0(0 ; 37)^{\mathrm{a}}$ & $0(0 ; 37)^{\mathrm{a}}$ \\
\hline & $\begin{array}{l}\text { Without chewing } \\
\text { simulation }\end{array}$ & $75(33 ; 97)^{\mathrm{b}}$ & $12.5(0 ; 53)^{\mathrm{a}}$ & $12.5(0 ; 53)^{\mathrm{a}}$ \\
\hline \multirow[t]{2}{*}{ Tetric EvoCeram } & $\begin{array}{l}\text { With chewing } \\
\text { simulation }\end{array}$ & $0(0 ; 37)^{\mathrm{a}}$ & $12,5(0 ; 53)^{a}$ & $87,5(46 ; 100)^{b}$ \\
\hline & $\begin{array}{l}\text { Without chewing } \\
\text { simulation }\end{array}$ & $12.5(0 ; 53)^{\mathrm{a}}$ & $0(0 ; 37)^{\mathrm{a}}$ & $87.5(46 ; 100)^{b}$ \\
\hline \multirow[t]{2}{*}{ Sound human molars } & $\begin{array}{l}\text { With chewing } \\
\text { simulation }\end{array}$ & $50(14 ; 85)^{\mathrm{b}}$ & $50(14 ; 85)^{b}$ & $0(0 ; 37)^{\mathrm{a}}$ \\
\hline & $\begin{array}{l}\text { Without chewing } \\
\text { simulation }\end{array}$ & $87.5(46 ; 100)^{\mathrm{c}}$ & $12.5(0 ; 53)^{\mathrm{a}}$ & $0(0 ; 37)^{\mathrm{a}}$ \\
\hline
\end{tabular}

${ }^{\mathrm{a}-\mathrm{c}}$ Indicate significant differences between relative frequencies among all tested groups within one fracture type

that far lower forces are sufficient for failure of the tooth to occur [27]. Consequently, a major restoration or a root canal therapy is indicated or even in the worst case, the affected tooth must be extracted. Also, occlusal overloading due to bruxism, accidental trauma, adverse cusp-fossa relationship, inadequate restoration planning, manufacturing defects, or material fatigue can cause a fracture [28].

To be able to predict and prevent material failure, Weibull statistics is a convenient tool in dentistry for comparing the flaw size distribution as well as flexural strength of different specimen sizes, stress configurations, and testing conditions [14]. The Weibull modulus $m$ indicates the spread of the distribution, so the higher the value, the smaller the dispersion and better the structural reliability of the material. In this study, for the groups with performed chewing simulation, the 3D printed material KET showed the lowest Weibull modulus, whereas the milled material JUV had the highest one. This could be explained by a manufacturing process of JUV under controlled industrial conditions that provides a homogeneous structure and high reliability. It is unclear why KET presented such a low Weibull modulus and thus the lowest reliability and fatigue resistance. This might be explained by a high water absorption during water storage in the incubator or chewing simulator. Unfortunately, again, data about the water absorption capacity, for example, by the manufacturer is missing.

TET showed the highest $m$ value for the groups without chewing simulation, which is remarkable, as it is a direct filling material, which, due to the incremental application, always shows minimal inhomogeneities, and therefore, a low $m$ value could be expected. Apparently, it was processed homogeneously in this investigation.

In terms of fracture types, all indirect restorations as well as sound molars showed tooth fractures, indicating a strong coherent connection within the restoration material respectively hard tooth tissue. The single layers of the $3 \mathrm{D}$ printed inlays seemed to be solidly fused due to the high melting 
temperatures. The high forces applied during the test were instantly transmitted to the tooth, resulting in a fracture. As PEEK has a lower Young's modulus than dentin (13 GPa, [29]) and enamel (72.7-87.5 GPa, [30]), tensile stress is concentrated and transmitted to the tooth under axial compressive stress, which leads to fracture [31]. Although TET also has a lower Young's modulus than the tooth structure, the fillings fractured during the measurements. One explanation might be that a fracture can spread more easily between the single polymerized parts due to unavoidable minimal inhomogeneities [32].

The teeth of this study fractured completely as well as cusp fractures occurred, which is rather explained by the irregular anatomical shapes of the used molars. Each natural tooth is individual with regard to the configuration of the occlusal surface, the size of the cusps, level of calcification, and location of the pulp chamber, which all have a decisive influence on the fracture type and fracture load, also represented by a high standard deviation in this investigation. Sheen et al. observed a higher fracture load for teeth of young men and no significant differences between mandibular and maxillary teeth [33]. In future studies, teeth of almost the same size, gender, and age range should be selected for enhanced comparability.

As the results presented, there were no major differences in fracture load values between printed and milled inlays. However, the printed inlays required an intensive postprocessing care. After removing the support structures, the final occlusal surface differed from the designed one and had to be re-contoured. The basal surface and the sides of the inlay had to be adapted in quite an intensive manner for being able to insert it into the cavity. As a result, a quite large cement gap was mostly created, which is susceptible to microleakage in vivo [34]. On the other hand, it was found that the fracture load is not affected by the thickness of the cement gap and internal fit, only by the quality of the margin [35]. Apart from the good mechanical properties, the poor esthetics of the PEEK inlays has to be criticized with regard to a brownishgray color. In order to achieve a tooth-colored translucent appearance, veneering is necessary, whereas a digital veneering method presented the highest fracture load [36].

The fact that the fracture load values exceeded the chewing forces can also be explained by the materials used for adhesive luting in this study. Thus airborne particle abrasion increases the surface area, which enables better penetration of the adhesive and ensures a solid microretentive bonding [37]. Due to the fact that visio.link is MMA (methyl methacrylate)-based and contains PETIA (pentaerythritol triacrylate), it has superior properties compared with other adhesive systems for PEEK [38]. The application of Syntac with Variolink is also a proven combination for adhesive luting of indirect restorations, which have achieved excellent results [39].
Fatigue resistance of dental materials is a very important factor when selecting a suitable material for a restoration, which was examined in the present study by chewing simulation. In order to increase the clinical relevance, chewing simulation with combined thermal cycling was used as an aging process in order to carry out a simultaneous mechanical and thermal stress test of the restored teeth. The 1.2 million chewing cycles applied correspond to 5 years of clinical practice and offer sufficient clinical relevance with regard to the survival rate of dental restorations [16]. Surprisingly, this fatigue process had no impact on the fracture load of the tested molars, so all materials revealed sufficient chewing resistance and the second null hypothesis had to be accepted. However, the teeth were only loaded with $50 \mathrm{~N}$ during the simulation, whereby physiologically higher chewing forces should rather be used. To develop a chewing simulator with a stable function using such high weights is quite a challenge. Teeth are constantly in contact with salvia in the oral environment, which was not practiced in this study. Storage and chewing simulation with physiological saliva could have yielded even better values [40].

Compared with other indirect materials, inlays out of yttrium-stabilized zirconia ceramic showed comparable fracture resistance to intact teeth of up to $1646 \mathrm{~N}$ due to the high compressive strength and transformation toughening of this ceramic [41]. Inlays made out of resin composite and lithium disilicate glass ceramic revealed lower values than intact teeth, whereas composite ones had the lowest fracture strength due to a minor Young's modulus of elasticity and rigidity [31].

The present investigation demonstrated the first steps towards AM of dental restorations out of PEEK via FLM and has shown promising results regarding mechanics and chewing resistance. Therefore, a huge potential in future applications can be expected. However, technical improvements on the printer side with regard to accuracy, detailed information about the filament composition to explain and predict the mechanical behavior, and in vivo clinical studies are mandatory.

\section{Conclusion}

Within the limitations of this investigation, the following conclusions can be made:

- All 3D printed and milled indirect PEEK inlays as well as the direct resin composite fillings showed a higher fracture load than the expected physiological and maximum chewing forces in the molar region, whereas sound molars demonstrated the highest fracture load of up to $2981 \mathrm{~N}$.

- Chewing simulation with combined thermal cycling had no impact on the fracture load of the tested specimens. 
- A quite extensive post-processing had to be executed especially for the printed inlays.

- All 3D printed PEEK indirect inlays stayed intact after the fracture load test.

Acknowledgments The authors would like to acknowledge KUMOVIS for providing the 3D printer HTRD1.2 and the PEEK filaments. We are also grateful to Ivoclar Vivadent and Gebr. Brasseler for material support of this study.

Funding Information Open Access funding provided by Projekt DEAL.

\section{Compliance with ethical standards}

Conflict of interest The authors declare that they have no conflict of interest.

Ethical approval This article does not contain any studies with human participants or animals performed by any of the authors.

Open Access This article is licensed under a Creative Commons Attribution 4.0 International License, which permits use, sharing, adaptation, distribution and reproduction in any medium or format, as long as you give appropriate credit to the original author(s) and the source, provide a link to the Creative Commons licence, and indicate if changes were made. The images or other third party material in this article are included in the article's Creative Commons licence, unless indicated otherwise in a credit line to the material. If material is not included in the article's Creative Commons licence and your intended use is not permitted by statutory regulation or exceeds the permitted use, you will need to obtain permission directly from the copyright holder. To view a copy of this licence, visit http://creativecommons.org/licenses/by/4.0/.

\section{References}

1. Dawood A, Marti Marti B, Sauret-Jackson V, Darwood A (2015) 3D printing in dentistry. Br Dent J:521-529. https://doi.org/10. 1038/sj.bdj.2015.914

2. Reymus M, Fotiadou C, Kessler A, Heck K, Hickel R, Diegritz C (2019) 3D printed replicas for endodontic education. Int Endod J 1: 123-130. https://doi.org/10.1111/iej.12964

3. Javaid M, Haleem A (2019) Current status and applications of additive manufacturing in dentistry: a literature-based review. J Oral Biol Craniofac Res 3:179-185. https://doi.org/10.1016/j. jobcr.2019.04.004

4. Ngo TD, Kashani A, Imbalzano G, Nguyen KTQ, Hui D (2018) Additive manufacturing (3D printing): a review of materials, methods, applications and challenges. Compos B Eng:172-196. https://doi.org/10.1016/j.compositesb.2018.02.012

5. van Noort R (2012) The future of dental devices is digital. Dent Mater 1:3-12. https://doi.org/10.1016/j.dental.2011.10.014

6. Valentan B, Kadivnik Z, Brajlih T, Anderson A, Igor D (2013) Processing poly (ether etherketone) on a $3 \mathrm{~d}$ printer for thermoplastic modelling. Mater Tehnol 6:715-721

7. Kurtz SM, Devine JN (2007) PEEK biomaterials in trauma, orthopedic, and spinal implants. Biomaterials 32:4845-4869. https://doi. org/10.1016/j.biomaterials.2007.07.013

8. Haleem A, Javaid M (2019) Polyether ether ketone (PEEK) and its manufacturing of customised 3D printed dentistry parts using additive manufacturing. Clin Epidemiol Glob Health. https://doi. org/10.1016/j.cegh.2019.03.001

9. Bathala L, Majeti V, Rachuri N, Singh N, Gedela S (2019) The role of polyether ether ketone (Peek) in dentistry-a review. J Med Life 1: 5-9. https://doi.org/10.25122/jml-2019-0003

10. Vaezi M, Yang S (2015) Extrusion-based additive manufacturing of PEEK for biomedical applications. Virtual and Physical Prototyping 3:123-135. https://doi.org/10.1080/17452759.2015. 1097053

11. Mondelli J, Sene F, Ramos RP, Benetti AR (2007) Tooth structure and fracture strength of cavities. Braz Dent J 2:134-138

12. Larson TD, Douglas WH, Geistfeld RE (1981) Effect of prepared cavities on the strength of teeth. Oper Dent 1:2-5

13. Coelho-de-Souza FH, Camacho GB, Demarco FF, Powers JM (2008) Fracture resistance and gap formation of MOD restorations: influence of restorative technique, bevel preparation and water storage. Oper Dent 1:37-43. https://doi.org/10.2341/07-27

14. Quinn JB, Quinn GD (2010) A practical and systematic review of Weibull statistics for reporting strengths of dental materials. Dent Mater 2:135-147. https://doi.org/10.1016/j.dental.2009.09.006

15. Weibull W (1951) A statistical distribution function of wide applicability. J Appl Mech 3:293-297

16. Rosentritt M, Behr M, van der Zel JM, Feilzer AJ (2009) Approach for valuating the influence of laboratory simulation. Dent Mater 3: 348-352. https://doi.org/10.1016/j.dental.2008.08.009

17. Bütikofer L, Stawarczyk B, Roos M (2015) Two regression methods for estimation of a two-parameter Weibull distribution for reliability of dental materials. Dent Mater 2:e33-e50. https:// doi.org/10.1016/j.dental.2014.11.014

18. Geigy WT, Statistik T (1980) vol 8. CIBA-GEIGY Limited, Basel

19. Fontijn-Tekamp FA, Slagter AP, Van Der Bilt A, Van THMA, Witter DJ, Kalk W, Jansen JA (2000) Biting and chewing in overdentures, full dentures, and natural dentitions. J Dent Res 7: 1519-1524. https://doi.org/10.1177/00220345000790071501

20. Helkimo E, Carlsson G, Helkimo M (1977) Bite force and state dentition. Acta Odontol Scand 6:297-303. https://doi.org/10. 3109/00016357709064128

21. Waltimo A, Könönen M (1995) Maximal bite force and its association with signs and symptoms of craniomandibular disorders in young Finnish non-patients. Acta Odontol Scand 4:254-258. https://doi.org/10.3109/00016359509005982

22. Ahlberg JP, Kovero OA, Hurmerinta KA, Zepa I, Nissinen MJ, Könönen MH (2003) Maximal bite force and its association with signs and symptoms of TMD, occlusion, and body mass index in a cohort of young adults. Cranio 4:248-252. https://doi.org/10.1080/ 08869634.2003.11746258

23. Rinaldi M, Ghidini T, Cecchini F, Brandao A, Nanni F (2018) Additive layer manufacturing of poly (ether ether ketone) via FDM. Compos B Eng:162-172. https://doi.org/10.1016/j. compositesb.2018.03.029

24. Aggarwal V, Logani A, Jain V, Shah N (2008) Effect of cyclic loading on marginal adaptation and bond strength in direct vs. indirect class II MO composite restorations. Oper Dent 5:587-592. https://doi.org/10.2341/07-152

25. Liebermann A, Wimmer T, Schmidlin PR, Scherer H, Loffler P, Roos M, Stawarczyk B (2016) Physicomechanical characterization of polyetheretherketone and current esthetic dental CAD/CAM polymers after aging in different storage media. J Prosthet Dent 3: 321-328.e2. https://doi.org/10.1016/j.prosdent.2015.09.004

26. Mondelli J, Steagall L, Ishikiriama A, de Lima Navarro MF, Soares FB (1980) Fracture strength of human teeth with cavity preparations. J Prosthet Dent 4:419-422. https://doi.org/10.1016/00223913(80)90213-9

27. Reeh ES, Messer HH, Douglas WH (1989) Reduction in tooth stiffness as a result of endodontic and restorative procedures. $\mathrm{J}$ 
Endod 11:512-516. https://doi.org/10.1016/S0099-2399(89) 80191-8

28. Lubisich EB, Hilton TJ, Ferracane J (2010) Cracked teeth: a review of the literature. J Esthet Restor Dent 3:158-167. https://doi.org/10. 1111/j.1708-8240.2010.00330.x

29. Watts DC (1994) Elastic moduli and visco-elastic relaxation. J Dent 3:154-158

30. Habelitz S, Marshall SJ, Marshall GW, Balooch M (2001) Mechanical properties of human dental enamel on the nanometre scale. Arch Oral Biol 2:173-183. https://doi.org/10.1016/S00039969(00)00089-3

31. Costa AKF, Xavier TA, Noritomi PY, Saavedra G, Borges ALS (2014) The influence of elastic modulus of inlay materials on stress distribution and fracture of premolars. Oper Dent 4:E160-E170. https://doi.org/10.2341/13-092-1

32. Melo RA, Bispo AdSL, Barbosa GAS, Galvão MR, de Assunção IV, Souza ROdA, Borges BCD (2019) Morphochemical characterization, microhardness, water sorption, and solubility of regular viscosity bulk fill and traditional composite resins. Microsc Res Tech 9:1500-1506. https://doi.org/10.1002/jemt.23315

33. Sheen C-Y, Dong J-K, Brantley WA, Han DS (2019) A study of fracture loads and fracture characteristics of teeth. J Adv Prosthodont 3:187-192. https://doi.org/10.4047/jap.2019.11.3.187

34. Shetty M, Rajalakshmi S, Krishna Prasad D (2014) Comparison of marginal gap and microleakage in copy-milled and cad-milled zirconia copings bonded using light cure and chemical cure resin bonding systems. J Indian Prosthodont Soc 1:37-45. https://doi. org/10.1007/s13191-014-0359-x

35. Okutan M, Heydecke G, Butz F, Strub JR (2006) Fracture load and marginal fit of shrinkage-free $\mathrm{ZrSiO} 4$ all-ceramic crowns after chewing simulation. J Oral Rehabil 11:827-832. https://doi.org/ 10.1111/j.1365-2842.2006.01637.x
36. Taufall S, Eichberger M, Schmidlin PR, Stawarczyk B (2016) Fracture load and failure types of different veneered polyetheretherketone fixed dental prostheses. Clin Oral Investig 9: 2493-2500. https://doi.org/10.1007/s00784-016-1777-4

37. Uhrenbacher J, Schmidlin PR, Keul C, Eichberger M, Roos M, Gernet W, Stawarczyk B (2014) The effect of surface modification on the retention strength of polyetheretherketone crowns adhesively bonded to dentin abutments. J Prosthet Dent 6:1489-1497. https:// doi.org/10.1016/j.prosdent.2014.05.010

38. Stawarczyk B, Taufall S, Roos M, Schmidlin PR, Lümkemann N (2018) Bonding of composite resins to PEEK: the influence of adhesive systems and air-abrasion parameters. Clin Oral Investig 2:763-771. https://doi.org/10.1007/s00784-017-2151-x

39. Frankenberger R, Krämer N, Appelt A, Lohbauer U, Naumann M, Roggendorf MJ (2011) Chairside vs. labside ceramic inlays: effect of temporary restoration and adhesive luting on enamel cracks and marginal integrity. Dent Mater 9:892-898. https://doi.org/10.1016/ j.dental.2011.05.007

40. Liebermann A, Ilie N, Roos M, Stawarczyk B (2017) Effect of storage medium and aging duration on mechanical properties of self-adhesive resin-based cements. J Appl Biomater Funct Mater 3:e206-e214. https://doi.org/10.5301/jabfm.5000362

41. Wafaie RA, Ibrahim Ali A, Mahmoud SH (2018) Fracture resistance of prepared premolars restored with bonded new lab composite and all-ceramic inlay/onlay restorations: laboratory study. J Esthet Restor Dent 3:229-239. https://doi.org/10.1111/jerd.12364

Publisher's note Springer Nature remains neutral with regard to jurisdictional claims in published maps and institutional affiliations. 